\title{
Antenatal corticosteroids and cardiometabolic outcomes in adolescents born with very low birth weight
}

\author{
Lisa K. Washburn ${ }^{1,2}$, Patricia A. Nixon ${ }^{1,3}$, Beverly M. Snively ${ }^{4}$, Gregory B. Russell ${ }^{4}$, Hossam A. Shaltout ${ }^{2,5,6}$, \\ Andrew M. South ${ }^{1,2}$ and T. Michael O'Shea ${ }^{7}$
}

BACKGROUND: Exposure to antenatal corticosteroids (ANCS) is associated with adverse cardiometabolic outcomes in animal models; however, long-term outcomes in clinical studies are not well characterized. We hypothesized that exposure to ANCS would be associated with markers of increased cardiometabolic risk in adolescents born with very low birth weight (VLBW).

METHODS: In an observational cohort of 186 14-year-old adolescents born with VLBW, we measured resting blood pressure (BP), BP response to cold, ambulatory BP, and anthropometrics; performed dual-energy X-ray absorptiometry; and analyzed blood samples for uric acid, cholesterol, glycated hemoglobin, and high-sensitivity C-reactive protein. Multivariate analyses were used to evaluate associations with ANCS, adjusting for race, sex, and maternal hypertensive pregnancy.

RESULTS: There were no ANCS group differences in BP measures or blood biomarkers. Compared with adolescents unexposed to ANCS, those exposed to ANCS were taller (exposed-unexposed mean difference $3.1 \mathrm{~cm}$ (95\% confidence interval (Cl) 0.7, 5.5)) and had decreased waist-to-height ratio (exposed-unexposed mean difference - $0.03(95 \% \mathrm{Cl}$ $-0.058,-0.002)$ ). Males exposed to ANCS had lower total cholesterol (exposed-unexposed mean difference - $0.54 \mathrm{mmol} / \mathrm{l}(95 \% \mathrm{Cl}-0.83,-0.06))$.

CONCLUSION: Among adolescents born with VLBW, ANCS exposure was not associated with markers of increased cardiometabolic risk.

I n the United States (US), treatment with corticosteroids has been recommended since 1994 for pregnant women expected to deliver before 34 weeks to reduce mortality and morbidity in the offspring $(1,2)$. Preclinical studies of antenatal corticosteroid (ANCS) treatment have raised concerns about long-term adverse effects of ANCS on blood pressure (BP) and cardiometabolic risk in the offspring (3-6).
Clinical studies have not detected associations of ANCS with an overt cardiometabolic disease $(7,8)$, other than possible alterations in BP, vascular stiffness, and glucose metabolism (9-11). In the largest follow-up study of patients from a randomized controlled trial of ANCS, the mean gestational age at birth was 34 weeks ((ref. 11)). Information about ANCS effects at earlier gestational ages is limited to studies with small sample sizes and/or limited racial diversity. In addition, cohorts with follow-up into adolescence or adulthood were born in the late 1960s to early 1980s.

Currently, almost all infants born in the US with very low birth weight (VLBW) are exposed to ANCS, and care has evolved such that fetuses are exposed to ANCS at earlier gestational ages. Contemporary survivors of preterm birth are maturing in the epidemic of obesity, potentially exposing them to a "second hit" that might potentiate putative programming effects of ANCS (12). Thus, we recruited a racially diverse and contemporary cohort of adolescents born prematurely with VLBW to study the effects of ANCS exposure on BP and cardiometabolic risk factors.

\section{METHODS}

\section{Study Design}

The study sample was derived from a cohort of consecutive VLBW singleton births at the regional perinatal center in Forsyth County, North Carolina from 1 January 1992 to 30 June 1996 who had no major congenital malformations and returned for evaluation at 1 year adjusted age. Figure 1 describes the cohort's participation in the follow-up study. We estimated that a total sample of 158 (79 in each ANCS group) would be needed to provide $90 \%$ statistical power to detect a between-group difference in the primary outcome, resting auscultatory systolic BP (SBP), of $4 \mathrm{~mm} \mathrm{Hg}$ (alpha $=0.05$, two-sided testing). The $4 \mathrm{~mm} \mathrm{Hg}$ difference used for determining sample size is the difference reported by Doyle et al. (9) in a study of VLBW individuals. As ANCS exposure was determined post enrollment, the study sample exceeded our target because of continuous accrual of participants. This study was approved by the Wake Forest School of Medicine and the Forsyth Medical Center Institutional Review Boards. Informed consent was obtained from parents or legal guardians, and participants gave assent.

Information about the pregnancy including ANCS exposure (betamethasone and/or dexamethasone), maternal hypertension

\footnotetext{
'Department of Pediatrics, Wake Forest School of Medicine, Winston-Salem, North Carolina; ${ }^{2}$ Hypertension and Vascular Research, Cardiovascular Sciences Center, Wake Forest School of Medicine, Wake Forest University, Winston-Salem, North Carolina; ${ }^{3}$ Department of Health and Exercise Science, Wake Forest University, Winston-Salem, North Carolina; ${ }^{4}$ Division of Public Health Sciences, Department of Biostatistical Sciences, Wake Forest University, Winston-Salem, North Carolina; ${ }^{5}$ Department of Obstetrics and Gynecology, Wake Forest University, Winston-Salem, North Carolina; ${ }^{6}$ Department of Pharmacology and Toxicology, School of Pharmacy, University of Alexandria, Alexandria, Egypt; ${ }^{7}$ Department of Pediatrics, University of North Carolina School of Medicine, Chapel Hill, North Carolina. Correspondence: Lisa K. Washburn (liwashbu@wakehealth.edu) Received 31 October 2016; accepted 24 May 2017; advance online publication 21 June 2017. doi:10.1038/pr.2017.133
} 


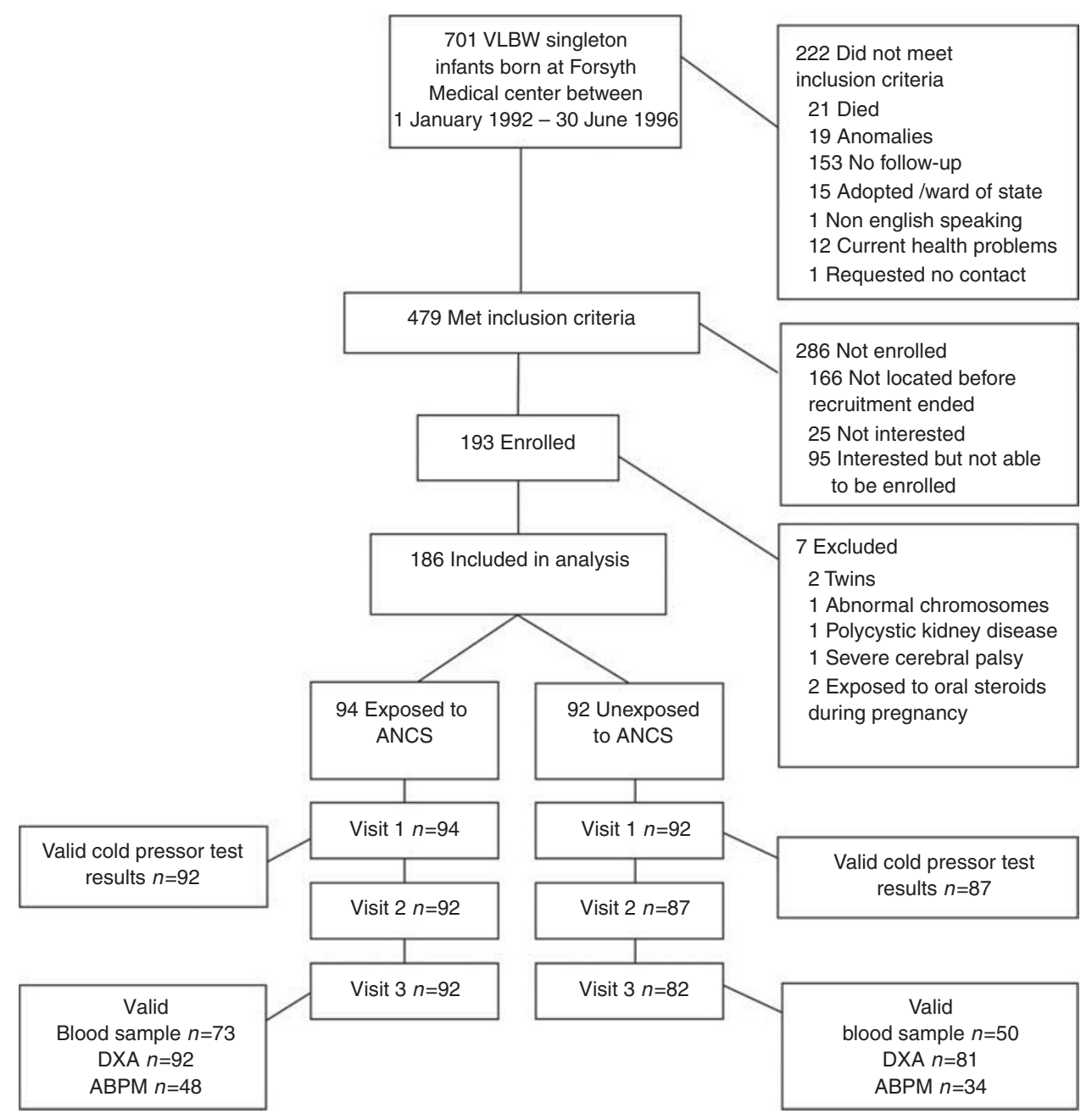

Figure 1. Eligibility, enrollment, and follow-up of the study population. ABPM, ambulatory blood pressure monitoring; ANCS, antenatal corticosteroid exposure; DXA, dual-energy X-ray absorptiometry; VLBW, very low birth weight.

during pregnancy, and type of delivery was obtained by review of medical records or from research databases. We excluded two participants whose mothers were treated with steroids during pregnancy for other medical conditions.

To estimate gestational age, we used, in order of priority, a firsttrimester ultrasound, the mother's last menstrual period, or clinical assessment of the neonate. As an index of fetal growth, we used birth weight $z$-score, calculated using US natality data (13). Birth weight and postnatal dexamethasone treatment to prevent BPD (defined as use of supplemental oxygen at 36 weeks' corrected gestational age) were obtained from review of the participants' medical record. As potential indicators of perinatal social economic status, we used the mother's marital status (married or non-married) and education status ( $\leq 12$ or $>12$ years), and, at the age of 14 years, we used Medicaid health insurance. The participant's race was categorized as black or non-black, based on the report of the parent or guardian at the 14-year visit. $Z$-scores and percentiles for measurements made at 14 years were derived using Epi Info (Centers for Disease Control, Atlanta, Georgia) (14). We categorized body mass index (BMI) $\geq 85^{\text {th }}$ percentile as overweight/obese (15). Pubertal maturation status was assessed in private using self-completed questionnaires based on Tanner staging for pubic hair, breast development in females, and genital development in males (16). Family history of cardiovascular disease was determined by the report of maternal or paternal hypertension, stroke, or heart attack submitted by the parent or guardian. Current medication use was reported by a parent or guardian and the participants.

Participants were examined for three visits during their 15th year of life. The half day visits were performed in a General Clinical Research Center. Participants were asked to refrain from caffeinecontaining beverages for $24 \mathrm{~h}$ before the visit. At each visit, BP was measured in the right arm with a mercury sphygmomanometer by the nursing staff certified in BP measurement using guidelines established by the National High Blood Pressure Education Program Working Group on Hypertension Control in Children and Adolescents (17). Proper cuff size was determined using mid-upper arm circumference. Participants were seated quietly for $5 \mathrm{~min}$ with the back supported, the forearm at the heart level, and feet flat on the floor. The average of three measurements was used to estimate SBP and diastolic BP. The average of five resting oscillometric BP measurements was recorded using the same procedure with the Dinamap Pro 100 GE Medical Systems (Milwaukee, WI, USA) (18).

The BP response to forehead cold stimulation was performed at the first visit following the procedures of Dysart et al. (19). During the 11th, 13th, and 15th minute of rest, baseline BP measurements were made using the Dinamap Pro 100 (Critikon). A bag of ice water was placed on the subject's forehead for $1 \mathrm{~min}$. At the end of the minute, $\mathrm{BP}$ was measured, and the bag was removed. The difference between the peak BP and the average of the three baseline BP measures was calculated. 
Ambulatory BP monitoring was utilized in the non-dominant arm after the third visit (Spacelabs 90207, Redmond, WA). Participants were asked to wear the monitor for $24 \mathrm{~h}$ and to keep a diary of their activities. The monitors were programmed to inflate every $20 \mathrm{~min}$ from $7 \mathrm{AM}$ to $9 \mathrm{PM}$ and every $30 \mathrm{~min}$ from 9 PM to $7 \mathrm{AM}$. Studies with at least $70 \%$ successful readings and those with at least one reading every hour were analyzed. The mean of successful daytime and nighttime readings was calculated using self-reported sleep and awake times, and percentages of nocturnal SBP and diastolic BP decline were determined. BP load was defined as the proportion of measurements above the 95th percentile for age, sex, and height (20).

In participants willing to undergo venipuncture, a non-fasting sample of blood was obtained at the third visit. Total and high density lipoprotein (HDL) cholesterol and uric acid concentrations were determined enzymatically, and ELISA (ALPCO, Windham, $\mathrm{NH}$ ) was used to measure high-sensitivity C-reactive protein concentration. Glycated hemoglobin was determined using Roche Tina-quant assay.

Measurements of height (to the nearest hundredth of a centimeter using a wall-mounted stadiometer) and weight (to the nearest tenth

Table 1. Characteristics of participants (mean \pm SD or count (\%))

\begin{tabular}{|c|c|c|c|}
\hline & ANCS $+(N=94)$ & ANCS - $(N=92)$ & $P$ value \\
\hline \multicolumn{4}{|l|}{ Perinatal } \\
\hline $\begin{array}{l}\text { Gestational age, } \\
\text { weeks }\end{array}$ & $27.7 \pm 2.3$ & $27.7 \pm 2.9$ & 0.93 \\
\hline Birth weight, $g$ & $1,029 \pm 268$ & $1,054 \pm 265$ & 0.52 \\
\hline $\begin{array}{l}\text { Birth weight } \\
z \text {-score }\end{array}$ & $-0.34 \pm 0.74$ & $-0.21 \pm 0.91$ & 0.28 \\
\hline SGA & $7(7)$ & $12(13)$ & 0.23 \\
\hline Cesarean delivery & $55(59)$ & $39(42)$ & 0.040 \\
\hline $\begin{array}{l}\text { Hypertensive } \\
\text { pregnancy }\end{array}$ & $40(43)$ & $26(28)$ & 0.047 \\
\hline Male & $45(48)$ & $39(42)$ & 0.47 \\
\hline Black & $27(29)$ & $51(55)$ & 0.0003 \\
\hline $\begin{array}{l}\text { Dexamethasone } \\
\text { for } \mathrm{BPD}^{\mathrm{b}}\end{array}$ & $22(23)$ & $12(13)$ & 0.088 \\
\hline BPD & $23(25)$ & $25(27)$ & 0.73 \\
\hline $\begin{array}{l}\text { Maternal education } \\
\leq 12 \text { years }\end{array}$ & 43/91(47) & $53 / 78(68)$ & 0.008 \\
\hline $\begin{array}{l}\text { Non-married } \\
\text { mother }\end{array}$ & $29(31)$ & $53(58)$ & 0.0004 \\
\hline
\end{tabular}

Age 14 years

\begin{tabular}{|c|c|c|c|}
\hline $\begin{array}{l}\text { Tanner genitalia/ } \\
\text { breast } \geq 4^{c}\end{array}$ & $75(81)$ & $71(80)$ & 1.0 \\
\hline $\begin{array}{l}\text { Tanner pubic } \\
\text { hair } \geq 4^{c}\end{array}$ & e & 79 (89) & 0.30 \\
\hline $\begin{array}{l}\text { Family history } \\
\text { of CV disease }\end{array}$ & $49(52)$ & $51(55)$ & 0.66 \\
\hline Medicaid $^{d}$ & $35(38)$ & $43(49)$ & 0.18 \\
\hline $\begin{array}{l}\text { Stimulant } \\
\text { medication }\end{array}$ & $11(12)$ & $8(9)$ & 0.63 \\
\hline
\end{tabular}

of a kilogram using a digital platform scale) were made at each study visit in triplicate with participants wearing light clothing and no shoes. The averages of each measurement were used for analysis. At the third visit, a nutritionist measured waist circumference (to the nearest tenth of a centimeter with a measuring tape according to the procedures of National Health and Nutrition Examination Survey III) (21) and triceps and subscapular skinfold thicknesses (using a Lange skinfold caliper) (22). Fat mass, fat-free mass, and bone mineral content were assessed using a Delphi dual-energy X-ray absorptiometer (Hologic, Bedford, MA) equipped with a pediatric software. Lean body mass was calculated by subtracting bone mineral content from total fat-free mass.

\section{Statistical Analysis}

Characteristics were compared using two-sample $t$ - and Fisher's Exact tests between ANCS-exposed and ANCS-unexposed study participants and between eligible VLBW patients who were enrolled and not enrolled in the study. Outcome measures that were not approximately normally distributed were transformed prior to analysis using logarithmic or square root transformation as indicated. To adjust for potential confounding and other variables, multiple regression modeling approaches were used, including general linear regression for continuous outcomes and logistic regression for dichotomous outcomes. Outcomes that were measured across multiple participant visits were modeled based on a general linear regression as well, but with a random effect to portray individual differences, and with a first-order autocorrelation structure for the repeated measures within participants across visits. Covariate selection was based on prior reported relationships in the literature, including an ANCS $\times$ BMI interaction term, which was included in models for BP measured at rest and in response to cold. The modeling procedures were repeated after stratifying separately by sex and by race. In an effort to differentiate the effect of race and socioeconomic status on ANCS group differences, analyses suggesting ANCS group differences when stratified by race were repeated stratifying by maternal marital status. To allow comparison with results reported by Doyle et al. (9), we estimated the exposedunexposed mean difference in SBP, adjusting for current weight, among non-black participants. Least squares means between ANCSexposed and ANCS-unexposed groups and adjusted odds ratios were used together with their corresponding 95\% confidence intervals (CIs) to evaluate associations with ANCS exposure. $P$ values $\leq 0.05$ were considered statistically significant. No correction for multiple testing was applied to outcomes, as those selected for analysis were related and were used to evaluate consistency across findings. All analyses were performed using SAS for Windows version 9.4 (SAS Institute, Cary, NC).

\section{RESULTS}

Compared with those eligible but not included in the study, the 186 participants had lower gestational age (mean \pm SD $27.7 \pm 2.6$ vs. $28.3 \pm 2.5$ weeks) and higher birth weight $z$-score $(-0.26 \pm 0.81$ vs. $-0.43 \pm 0.81)$, but were similar in birth weight, race, sex, and mode of delivery (results not shown). Participant characteristics are shown in Table 1.

For the 65 participants for whom complete data on ANCS exposure were available, all were exposed to betamethasone except one who received one dose each of betamethasone and dexamethasone, and one who received only dexamethasone. Of those exposed to multiple courses (two doses of betamethasone separated by 1 week), five received two courses and two received three courses. Caesarean delivery and maternal hypertension during pregnancy were more common in those exposed to ANCS. Non-married mothers, mothers with less than or equal to high school 


\section{Articles | washburn et al.}

Table 2. BP measurements at 14 years of age (mean \pm SD or count (\%))

\begin{tabular}{|c|c|c|c|c|}
\hline & ANCS+ & ANCS - & $\begin{array}{l}\text { Unadjusted } \\
\text { P value }\end{array}$ & $\begin{array}{l}\text { Adjusted mean difference }{ }^{\mathrm{b}} \text { (or odds ratio where noted; } \\
\qquad 95 \% \mathrm{Cl} \text { ) Pvalue }\end{array}$ \\
\hline Resting $B P^{\mathrm{C}}$ & $N=94$ & $N=92$ & & \\
\hline Auscultatory SBP, $\mathrm{mm} \mathrm{Hg}$ & $105.5 \pm 0.9$ & $104.4 \pm 0.9$ & 0.38 & $\begin{array}{c}0.4(-2.3,3.1) \\
P=0.77\end{array}$ \\
\hline Auscultatory DBP, $\mathrm{mm} \mathrm{Hg}$ & $61.7 \pm 0.7$ & $60.1 \pm 0.7$ & 0.13 & $\begin{array}{l}2.0(-0.2,4.2) \\
P=0.080\end{array}$ \\
\hline Oscillometric SBP, mm Hg & $108.9 \pm 0.9$ & $108.4 \pm 0.9$ & 0.71 & $\begin{array}{c}-0.7(-3.3,2.0) \\
P=0.62\end{array}$ \\
\hline Oscillometric DBP, mm Hg & $59.8 \pm 0.6$ & $60.1 \pm 0.6$ & 0.65 & $\begin{array}{l}-0.1(-1.8,1.6) \\
P=0.90\end{array}$ \\
\hline$B P$ response to cold & $N=92$ & $N=87$ & & \\
\hline SBP delta, mm Hg & $14.6 \pm 9.7$ & $14.2 \pm 10.7$ & 0.76 & $\begin{array}{c}0.2(-3.0,3.4) \\
P=0.91\end{array}$ \\
\hline DBP delta, $\mathrm{mm} \mathrm{Hg}$ & $6.9 \pm 6.7$ & $7.9 \pm 7.0$ & 0.31 & $\begin{array}{c}-0.7(-2.8,1.5) \\
P=0.55\end{array}$ \\
\hline Ambulatory $B P$ & $N=48$ & $N=34$ & & \\
\hline $24 \mathrm{~h} \mathrm{SBP}, \mathrm{mm} \mathrm{Hg}$ & $115.7 \pm 7.1$ & $114.8 \pm 7.1$ & 0.57 & $\begin{array}{l}0.6(-2.9,4.0) \\
P=0.75\end{array}$ \\
\hline $24 \mathrm{~h} \mathrm{DBP}, \mathrm{mm} \mathrm{Hg}$ & $65.8 \pm 5.1$ & $64.6 \pm 6.2$ & 0.34 & $\begin{array}{l}2.1(-0.6,4.8) \\
P=0.13\end{array}$ \\
\hline SBP load, $\%^{d}$ & $12.3 \pm 11.0$ & $11.9 \pm 9.7$ & 0.98 & $\begin{array}{c}0.14(-0.67,0.94), \\
P=0.73\end{array}$ \\
\hline DBP load, $\%^{d}$ & $11.3 \pm 8.8$ & $9.6 \pm 7.7$ & 0.27 & $0.40(-0.24,1.06)^{\mathrm{e}} P=0.21$ \\
\hline Nocturnal SBP dip $<10 \%{ }^{f}$ & $22(54)$ & $15(50)$ & 0.81 & $\begin{array}{l}2.1(0.6,6.8)^{g} \\
\quad P=0.22\end{array}$ \\
\hline Nocturnal DBP dip $<10 \%{ }^{f}$ & $7(17)$ & $2(7)$ & 0.29 & $\begin{array}{c}4.0(0.6,28.5)^{g} \\
P=0.16\end{array}$ \\
\hline \multicolumn{5}{|c|}{ 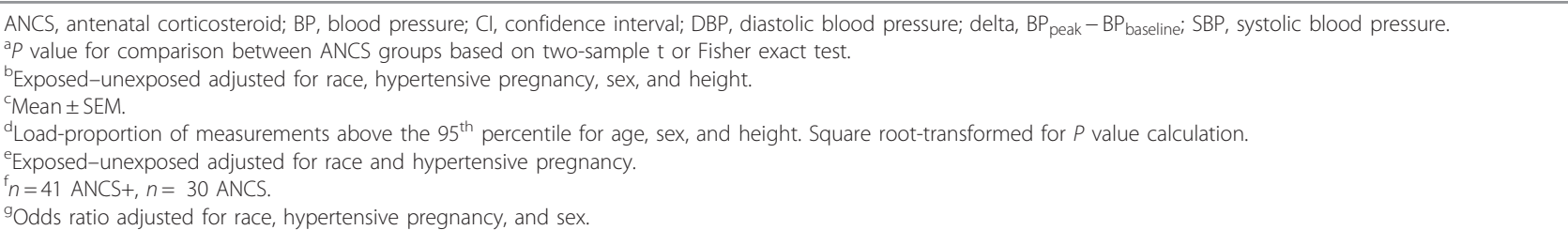 } \\
\hline
\end{tabular}

education, and mothers of black participants were less likely to be exposed to ANCS (Table 1). Race was related to maternal marital status $(P<0.0001)$ but not maternal education $(P=0.21)$.

At 14 years of age, 186 (94 exposed) participants completed one visit, 179 (92 exposed) completed two visits, and 174 (92 exposed) completed all three study visits. There were no group differences in the BP outcomes as shown in Table 2. Exclusion of participants treated with postnatal dexamethasone to prevent BPD did not alter the results (data not shown). Similarly, exclusion of BP measurements potentially affected by stimulant medications for attentiondeficit hyperactivity disorder did not affect the results. Although waist-to-height ratio (WHtR) at 14 years was positively correlated with auscultatory and oscillometric SBP $(r=0.25$ and $r=0.34$, respectively, $P<0.001)$, we did not detect significant ANCS $\times$ BMI interactions. When stratified by sex, ANCS-exposed females had higher resting auscultatory diastolic BP $(63.2 \pm 0.9$ vs. $60.7 \pm 0.9 \mathrm{~mm} \mathrm{Hg} ; P=0.072)$, which was attenuated when adjusted for race, height, and maternal hypertensive pregnancy. When stratified by race, ANCS-exposed non-black participants had higher auscultatory SBP $(106.0 \pm 1.1$ vs. $102.6 \pm 1.4 \mathrm{~mm} \mathrm{Hg} ; P=0.063)$, diastolic BP $(61.5 \pm 0.9$ vs. $58.6 \pm 1.2 \mathrm{~mm} \mathrm{Hg} ; P=0.065)$, and higher peak SBP response to cold stress $(128.5 \pm 12.6$ vs. $123.6 \pm 10.8 \mathrm{~mm} \mathrm{Hg} ; P=0.051)$. The ANCS group differences in non-blacks were attenuated when adjusted for sex, height, and maternal hypertensive pregnancy. However, resting auscultatory SBP was higher in ANCS-exposed non-blacks when current BMI replaced height in the model (exposedunexposed mean difference $3 \mathrm{~mm} \mathrm{Hg}$ (95\% CI 0.07, 6.9; $P=0.045)$ ). In contrast to results stratified by race, there were no ANCS group differences in BP outcomes when stratified by maternal marital status.

There were also no ANCS group differences in circulating biomarkers (Table 3). However, among males, ANCS exposure was associated with lower total cholesterol (exposed-unexposed mean difference $-0.54 \mathrm{mmol} / \mathrm{l}$ (95\% CI 


\section{ANCS and cardiometabolic outcomes}

Table 3. Biomarkers at 14 years of age (mean \pm SD)

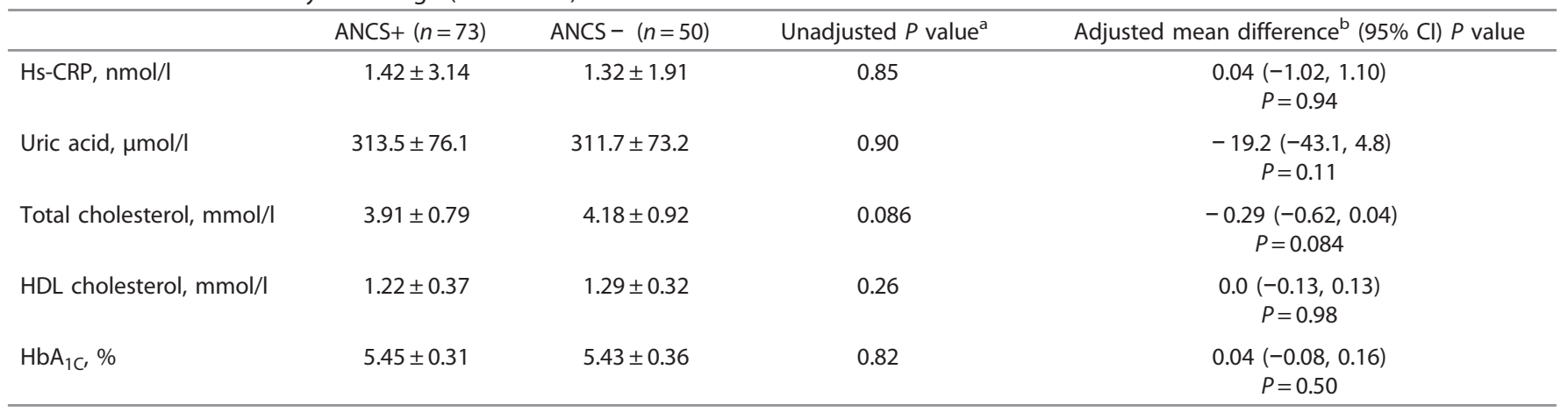

ANCS, antenatal corticosteroid; Cl, confidence interval; hs-CRP, high-sensitivity C-reactive protein; HbA 1 , glycated hemoglobin.

a $P$ value for comparison between ANCS groups based on two-sample $t$-test.

bexposed-unexposed adjusted for race, hypertensive pregnancy, and sex.

$-0.83,-0.06), \quad P=0.029)$ when adjusted for race and hypertensive pregnancy. This relationship was attenuated when adjusted for central adiposity (WHtR; exposedunexposed mean difference $-0.14 \mathrm{mmol} / \mathrm{l}(95 \% \mathrm{CI}-0.57$, $0.28), P=0.52)$.

Anthropometric measures of the participants at 14 years of age are shown in Table 4. Participants exposed to ANCS were taller, had a lower WHtR, and tended to have a lower sum of triceps and subscapular skinfold thicknesses. There were no ANCS group differences in body composition variables obtained by dual-energy X-ray absorptiometer. Three percent of each group were classified as underweight (BMI $<5$ th percentile) and about one-third of each group (29\% exposed, $37 \%$ unexposed; $P=0.27$ ) were classified as overweight (BMI $\geq 85$ th percentile). In subgroup analyses, the ANCS group differences in the sum of triceps and subscapular skinfold thicknesses were greater in non-blacks (exposedunexposed mean difference, $-8.7 \mathrm{~mm}(95 \% \mathrm{CI}-15.2,-2.2)$, $P=0.009$ ) than in blacks (exposed-unexposed mean difference, $1.3 \mathrm{~mm}$ (95\% CI -7.4, 10.1), $P=0.76$ ), adjusted for sex and hypertensive pregnancy, and in males (exposed-unexposed mean difference, $-7.5 \mathrm{~mm}$ (95\% CI $-15.1,0.2)$, $P=0.056)$ compared with those in females (exposedunexposed mean difference, $-0.9 \mathrm{~mm}$ ( $95 \%$ CI $-8.2,6.4$ ), $P=0.80$ ), adjusted for race and hypertensive pregnancy. In contrast to results stratified by race, there were no ANCS group differences in skinfold thicknesses when stratified by maternal marital status.

\section{DISCUSSION}

In a cohort of adolescents born with VLBW, we found no associations between exposure to ANCS and measures of resting $\mathrm{BP}$, ambulatory $\mathrm{BP}$ monitoring, or $\mathrm{BP}$ response to cold stress, total or HDL cholesterol, $\mathrm{HbA}_{1 \mathrm{c}}$, or uric acid. Exposure to ANCS was associated with increased height and decreased WHtR at 14 years of age. Among males, exposure to ANCS was associated with lower total cholesterol, and, among non-blacks, ANCS was associated with a lower sum of triceps and subscapular skinfold thickness.
Except for racial diversity and birth years, our study cohort is similar in birth weight, gestational age, and age at follow-up to that studied by Doyle et al. (9) in which the ANCS group had $4 \mathrm{~mm} \mathrm{Hg}$ higher SBP at the age of 14 years. In the only other study to describe an association between ANCS and BP during adolescence, SBP was 3-4 mm Hg lower among those exposed to ANCS (7). Similar to Doyle et al. (9), we found a positive association between SBP and adiposity at the age of 14 years, and when adjusted for current adiposity (Doyle et al. (9) adjusted for current weight $z$-score), we found that, among non-blacks, those exposed to ANCS had higher SBP. We also assessed the $\mathrm{BP}$ response to cold stress as a potential indicator of future BP and found no ANCS group difference $(23,24)$.

Kelly et al. (10) reported an association between ANCS and increased vascular stiffness in the aortic arch in young adults, despite there being no difference in peripheral BP. Similarly, we have described physiological (lower heart rate variability) and biochemical (increased ratio of urinary angiotensin II to angiotensin I-VII ) changes that could predispose ANCSexposed adolescents to higher BP $(25,26)$. Given these findings and the knowledge that programmed changes in BP amplify with age, differences in BP may emerge as our cohort ages (27).

In agreement with Doyle et al. (9), we found that VLBW adolescents exposed to ANCS were taller than their unexposed peers. No studies have described decreased adiposity in those exposed to ANCS. In contrast, Finken et al. (28) described an association of ANCS exposure and increased abdominal adiposity in young adults who had glucocorticoid receptor gene variant 363S. Likewise, preclinical models suggest that ANCS may be associated with increased adiposity (5). Our finding of decreased WHtR is driven by the increased height in the exposed group; however, there are trends for lower sum of triceps and subscapular skinfold thicknesses in the ANCS-exposed group as well. It is possible that ANCS group differences in height might be attributable to subtle differences in puberty that our selfassessment tool was not sensitive enough to detect; however, other studies have not found ANCS-associated differences in sexual maturity $(7,9)$. It is also possible that chronic illness might contribute to decreased height; however, we have 


\section{Articles | Washburn et al.}

Table 4. Anthropometrics at 14 years of age (mean \pm SD or count (\%))

\begin{tabular}{|c|c|c|c|c|}
\hline & ANCS $+(N=94)$ & ANCS - $(N=92)$ & Pvalue $^{\mathrm{a}}$ & $\begin{array}{l}\text { Adjusted mean difference }{ }^{b, c} \text { (or odds ratio where noted) }(95 \% \\
\qquad \mathrm{Cl}) P \text { value } N=186\end{array}$ \\
\hline Height, cm & $162.8 \pm 8.7$ & $159.7 \pm 9.3$ & 0.018 & $\begin{array}{l}3.1(0.7,5.5) \\
P=0.011\end{array}$ \\
\hline Weight, kg & $58.8 \pm 14.8$ & $59.9 \pm 18.3$ & 0.66 & $\begin{array}{c}-1.2(-6.2,3.7) \\
P=0.62\end{array}$ \\
\hline BMI, $\mathrm{kg} / \mathrm{m}^{2}$ & $22.1 \pm 5.0$ & $23.3 \pm 6.3$ & 0.14 & $\begin{array}{l}-1.2(-3.0,0.5) \\
P=0.15\end{array}$ \\
\hline BMI $\geq 85$ th percentile & $27(29)$ & $34(37)$ & 0.27 & $\begin{array}{l}0.65(0.34,1.26)^{d} \\
P=0.20\end{array}$ \\
\hline Waist circumference, cm & $78.0 \pm 13.3$ & $80.0 \pm 16.7$ & 0.40 & $\begin{array}{l}-2.9(-7.6,1.8) \\
P=0.23\end{array}$ \\
\hline Waist/height ratio & $0.478 \pm 0.079$ & $0.500 \pm 0.098$ & 0.106 & $\begin{array}{l}-0.030(-0.058,-0.002) \\
P=0.034\end{array}$ \\
\hline $\begin{array}{l}\text { Triceps+subscapular skinfold } \\
\text { thickness, mm }\end{array}$ & $30.3 \pm 16.7$ & $35.2 \pm 18.5$ & 0.072 & $\begin{array}{l}-4.8(-10.1,0.5) \\
P=0.076\end{array}$ \\
\hline$D X A$ & $n=92$ & $n=81$ & & \\
\hline Lean mass, kg & $42.5 \pm 9.8$ & $42.5 \pm 10.3$ & 0.99 & $\begin{array}{l}-0.1(-2.8,2.5) \\
P=0.93\end{array}$ \\
\hline Lean mass index, $\mathrm{kg} / \mathrm{m}^{2}$ & $15.9 \pm 2.7$ & $16.5 \pm 2.9$ & 0.18 & $\begin{array}{l}-0.6(-1.4,0.2) \\
P=0.15\end{array}$ \\
\hline Fat mass, kg & $15.4 \pm 8.7$ & $17.0 \pm 10.9$ & 0.29 & $\begin{array}{l}-1.8(-4.8,1.2) \\
P=0.23\end{array}$ \\
\hline Fat mass index, $\mathrm{kg} / \mathrm{m}^{2}$ & $5.9 \pm 3.3$ & $6.6 \pm 4.1$ & 0.18 & $\begin{array}{c}-0.8(-2.0,0.2) \\
P=0.13\end{array}$ \\
\hline \multicolumn{5}{|c|}{$\begin{array}{l}\text { ANCS, antenatal corticosteroid; BMI, body mass index; DXA, dual energy X-ray absorptiometry. } \\
{ }^{a} P \text { value for comparison between ANCS groups based on two-sample } t \text { or Fisher exact test. } \\
\text { b Exposed-unexposed adjusted for race, hypertensive pregnancy, and sex. } \\
{ }^{c} \text { General linear model least squares means. } \\
{ }^{d} \text { Odds ratio-adjusted for race and hypertensive pregnancy. }\end{array}$} \\
\hline
\end{tabular}

previously reported that ANCS was not associated with improved lung function at 14 years of age in this cohort (29). Mathai et al. (30) reported increased truncal fat in adults (especially males) who were born preterm to mothers who participated in the Auckland Steroid Trial. Although ANCSassociated effects on anthropometry were not found in followup of the Auckland Trial (11), it is possible that exposure to antenatal steroids at an earlier gestational age attenuates this presumed effect of prematurity. Our finding of an ANCSassociated decrease in adiposity in non-blacks might be explained by epigenetic and/or genetic variations in the response to ANCS. We have described racial differences in ANCS-associated changes in heart rate variability, and Myazek et al. described racial differences in the programming effects of low birth weight on cardiovascular risk factors at $7-21$ years of age $(25,31)$.

Consistent with prior studies of the relationship between biomarkers of adverse cardiovascular risk and ANCS, we did not detect ANCS group differences in total or HDL cholesterol levels, except among males, in whom ANCS was associated with lower total cholesterol $(8,10,11)$. We did not find any ANCS-associated differences in high-sensitivity C-reactive protein or serum uric acid. Others have described ANCS-associated alterations in glucose metabolism, both increased and decreased insulin resistance, and decreased beta cell function $(8,10,11)$. It is possible that our measure of $\mathrm{HbA}_{1 \mathrm{c}}$, a marker of elevated glucose in the prior 3 months, might not have been sensitive enough to detect abnormalities in insulin sensitivity.

Our finding that black mothers were less likely to be treated with ANCS has been described by others (32). Analyses to determine whether an indicator of socioeconomic statusmaternal marital status-explained the ANCS group differences we describe among non-blacks revealed that race does convey different information than marital status. We acknowledge that race provides information about multiple factors, including biological and socioeconomic factors. Racial differences in socioeconomic status are well described; however, multiple factors such as exposure to adversity over the life course, non-equivalence of socioeconomic indicators across races, racism, and increased exposure to psychological stressors suggest that race influences health outcomes in addition to socioeconomic status (33).

Our study is limited by its observational design and potential for selection bias; however, randomized trials of ANCS treatment and placebo are no longer ethical. Strengths of our study include multiple measurements of BP using both the auscultatory and oscillometric methods on three different 
days; measurement of several physiological and molecular markers related to regulation of $\mathrm{BP}$; and the inclusion of a multiracial contemporary cohort. As exposure to ANCS is increasing and occurring at earlier gestational ages, continued study of the long-term effects of ANCS on cardiovascular health is warranted.

\section{CONCLUSION}

ANCS exposure was not associated with higher BP or adverse cardiometabolic risk but was associated with increased height and decreased adiposity in 14-year olds born with VLBW.

\section{ACKNOWLEDGMENTS}

We thank the participants and their families, Patricia Brown, the research nurse, and Alice Scott, the study coordinator.

\section{STATEMENT OF FINANCIAL SUPPORT:}

Financial support was provided by National Institute of Child Health and Human Development PO1 HD047584; Clinical Research Unit of Wake Forest Baptist Medical Center MCRR/NIH MO1-RR07122 Novant Health, Forsyth Medical Center; Wake Forest School of Medicine, Department of Pediatrics Research Fund.

Disclosure: The authors declare no conflict of interest.

\section{REFERENCES}

1. Roberts D, Dalziel S. Antenatal corticosteroids for accelerating fetal lung maturation for women at risk of preterm birth. Cochrane Database Syst Rev 2006;19:CD004454.

2. Effect of corticosteroids for fetal maturation on perinatal outcomes. NIH consensus development panel on the effect of corticosteroids for fetal maturation on perinatal outcomes. JAMA 1995;273:413-8.

3. Shaltout HA, Rose JC, Chappell MC, Diz DI. Angiotensin-(1-7) deficiency and baroreflex impairment precede the antenatal betamethasone exposure-induced elevation in blood pressure. Hypertension 2012;59:453-8.

4. Figueroa JP, Rose JC, Massmann GA, Zhang J, Acuna G. Alterations in fetal kidney development and elevations in arterial blood pressure in young adult sheep after clinical doses of antenatal glucocorticoids. Pediatr Res 2005;58:510-5.

5. Berry MJ, Jaquiery AL, Oliver MH, Harding JE, Bloomfield FH. Antenatal corticosteroid exposure at term increases adult adiposity: an experimental study in sheep. Acta Obstet Gynecol Scand 2013;92:862-5.

6. Nyirenda MJ, Carter R, Tang JI, et al. Prenatal programming of metabolic syndrome in the common marmoset is associated with increased expression of 11ss-hydroxysteroid dehydrogenase type 1. Diabetes 2009;58:2873-9.

7. Dessens AB, Haas HS, Koppe JG. Twenty-year follow-up of antenatal corticosteroid treatment. Pediatrics 2000;105:E77.

8. Finken MJJ, Keijzer-Veen MG, Dekker FW, et al. Antenatal glucocorticoid treatment is not associated with long-term metabolic risks in individuals born before 32 weeks of gestation. Arch Dis Childhood 2008;93:F442-7.

9. Doyle LW, Ford GW, Davis NM, Callanan C. Antenatal corticosteroid therapy and blood pressure at 14 years of age in preterm children. Clin Sci 2000;98:137-42.

10. Kelly BA, Lewandowski AJ, Worton SA, et al. Antenatal glucocorticoid exposure and long-term alterations in aortic function and glucose metabolism. Pediatrics 2012;129:e1282-90.

11. Dalziel SR, Walker NK, Parag V, et al. Cardiovascular risk factors after antenatal exposure to betamethasone: 30 -year follow-up of a randomised controlled trial. Lancet 2005;365:1856-62.
12. Law CM, Shiell AW, Newsome CA, et al. Fetal, infant, and childhood growth and adult blood pressure: a longitudinal study from birth to 22 years of age. Circulation 2002;105:1088-92.

13. Oken E, Kleinman KP, Rich-Edwards J, Gillman MW. A nearly continuous measure of birth weight for gestational age using a United States national reference. BMC Pediatr 2003;3:6.

14. McDowell MA, Fryar CD, Hirsch R, Ogden CL. Anthropometric reference data for children and adults: U.S. population, 1999-2002. Adv Data 2005;361:1-5.

15. Barlow SE, Committee ATE. Expert committee recommendations regarding the prevention, assessment, and treatment of child and adolescent overweight and obesity: summary report. Pediatrics 2007;120: S164-92.

16. Taylor SJ, Whincup PH, Hindmarsh PC, Lampe F, Odoki K, Cook DG. Performance of a new pubertal self-assessment questionnaire: a preliminary study. Paediatr Perinat Epidemiol 2001;15:88-94.

17. Update on the 1987 task force report on high blood pressure in children and adolescents: a working group report from the National High Blood Pressure Education Program. National high blood pressure education program working group on hypertension control in children and adolescents. Pediatrics 1996;98:649-58.

18. Gillman MW, Cook NR. Blood pressure measurement in childhood epidemiological studies. Circulation 1995;92:1049-57.

19. Dysart JM, Treiber FA, Pflieger K, Davis H, Strong WB. Ethnic differences in the myocardial and vascular reactivity to stress in normotensive girls. Am J Hypertens 1994;7:15-22.

20. Wuhl E, Witte K, Soergel M, Mehls O, Schaefer F. Distribution of 24-h ambulatory blood pressure in children: normalized reference values and role of body dimensions. J Hypertens 2002;20:1995-2007.

21. NHANES III Anthropometric Procedures Video. Washington, DC: U.S. Government Printing Office, 2012 (http://www.cdc.gov/nchs/nhanes/ nhanes3/anthropometric_videos.htm.) Accessed 1996.

22. Lohman GT, Roche FA, Martorell R, et al. Skinfold Thicknesses. Champaign, IL: Human Kinetics Books, 1988.

23. Wood DL, Sheps SG, Elveback LR, Schirger A. Cold pressor test as a predictor of hypertension. Hypertension 1984;6:301-6.

24. Zhao Q, Gu D, Lu F, et al. Blood pressure reactivity to the cold pressor test predicts hypertension among Chinese adults: the GenSalt Study. Am J Hypertens 2015;28:1347-54.

25. Nixon PA, Washburn LK, Michael O'Shea T, et al. Antenatal steroid exposure and heart rate variability in adolescents born with very low birth weight. Pediatr Res 2017;81:57-62.

26. South AM, Nixon PA, Chappell MC, et al. Antenatal corticosteroids and the renin-angiotensin-aldosterone system in adolescents born preterm. Pediatr Res 2017;81:88-93.

27. Chen W, Srinivasan SR, Berenson GS. Amplification of the association between birthweight and blood pressure with age: the Bogalusa Heart Study. J Hypertens 2010;28:2046-52.

28. Finken MJ, Meulenbelt I, Dekker FW, et al. Abdominal fat accumulation in adults born preterm exposed antenatally to maternal glucocorticoid treatment is dependent on glucocorticoid receptor gene variation. J Clin Endocrinol Metab 2011;96:E1650-55.

29. Nixon PA, Washburn LK, O'Shea TM. Antenatal steroid exposure and pulmonary outcomes in adolescents born with very low birth weight. J Perinatol 2013;33:806-10.

30. Mathai S, Derraik JG, Cutfield WS, et al. Increased adiposity in adults born preterm and their children. PLoS ONE 2013;8:e81840.

31. Mzayek F, Sherwin R, Fonseca V, et al. Differential association of birth weight with cardiovascular risk variables in African- Americans and Whites: The Bogalusa heart study. Ann Epidemiol 2004;14:258-64.

32. Shankaran S, Lin A, Maller-Kesselman J, et al. Maternal race, demography and health care disparities impact risk for IVH in preterm neonates. J Pediatr 2014;164:1005-11.

33. Williams DR, Priest N, Anderson NB. Understanding associations among race, socioeconomic status, and health: patterns and prospects. Health Psychol 2016;35:407-11. 